\title{
Cause Analysis and Countermeasure Research on Construction Safety Accident
}

\author{
Weidong Liu \\ Applied Technology College of Dalian Ocean University, Dalian, Liaoning, China
}

\begin{abstract}
Keywords: Cause Analysis, Countermeasure Research, Construction Safety Accident
\end{abstract}
\begin{abstract}
With the vigorous development of Chinese construction market and the improvement of construction technology, more and more high-rise buildings, mechanized construction also increased, resulting in increasing the difficulty of construction. In the construction, the security issue is the most important, is the most direct reflection of people-oriented. Construction involves a wide range of complex construction personnel, mobility, coupled with the construction process is relatively complex, subject to external factors cannot help but in the construction process to produce safety incidents. Based on this, this paper analyzes the causes of safety accidents and put forward the main countermeasures to reduce the occurrence of safety accidents for reference.
\end{abstract}

\section{Introduction}

At present, China is in a period of large-scale economic construction, the scale of the construction industry increased year by year, Chinese construction industry in 2008 the output value of up to 5 trillion yuan, the construction industry added value of 1.4014 billion yuan, accounting for $5.7 \%$ of GDP. In the national economy in the fourth sector, has become the industry, agriculture, trade after the fourth pillar industry. However, with the construction of high, large, deep, new development, construction is increasingly difficult. The unconventional development of the construction industry has brought about the decline of the overall quality of construction services. The number of accidents and the number of deaths in the construction safety accidents have been high, and the safety of production in some areas is grim. Explore the reasons, mainly due to the low level of safety management in Chinese construction projects. Therefore, drawing on the international advanced safety management theory and experience, combined with Chinese national conditions, the construction project safety systematically analyzed and studied, proposed to prevent the construction safety management methods and measures, no doubt to prevent and reduce the occurrence of security incidents Very important theoretical and practical significance.

\section{Situation Analysis on the Safety Production in Chinese Construction}

The overall situation of the national construction safety production has stabilized and improved, reflecting that with the increase in the scale of the construction industry, the accident will be controlled. But the proportion of three accidents has increased, the number of deaths is still high, the type of accident is still the "five major injuries" based. During the period from 2004 to 2007, the number of deaths in the national construction accident, such as falling, construction collapse, object strike, machine damage and electric shock, accounted for $90.05 \%$ of the total number of accidents, including $46.25 \%$. The main reason for the construction safety is: First, the ideological understanding, some regional construction departments and some enterprises did not really establish the concept of safe development, not in accordance with the requirements of security work into the development plan and an important agenda. Second, business management, some construction enterprises and even some high-quality construction enterprises, extensive management methods, safety conditions do not meet the requirements of security investment seriously. Third, government regulation, some government departments in charge of lax enforcement, poor supervision, regulatory capacity and increasing the scale of construction does not meet the regulatory performance of layers of decay problems. Fourth, the responsibility of the main safety aspects of responsibility, some 
construction units and project supervision units on their own security responsibilities unclear, did not play the role of security management and supervision. Fifth, the construction market environment, unreasonable low bid, not according to the law to implement the construction process, illegal subcontracting, subcontracting, qualification and other phenomena are still relatively common. The construction industry, the quality of workers, Chinese construction industry first-line operating personnel to migrant workers and their safety awareness is relatively weak.

Through the analysis of the national construction safety situation from 2004 to 2007, it can be seen that the overall situation of construction safety production tends to stabilize, but the three major accidents are still frequent and the number of deaths is high, and the type of accidents is still. "In the case of regional change, although the number of accidents in some areas has declined, the number of deaths has increased. Among these types, the collapse of construction and the height of the fall is the main form of the accident, but also the main cause of death. Therefore, a comprehensive and objective analysis and study of the "five hurts" accident causes, characteristics and the law of the accident, for the scientific grasp of construction safety production situation, targeted to develop relevant policies, regulations and standards, supervision of construction safety production, reduce the occurrence of accidents has an important role.

\section{Causes Analysis on the Safety Accidents in Chinese Construction}

Construction safety management is not in place, the security system is not perfect and the safety responsibility is not implemented. There are many defects in the safety management of construction and construction. The construction supervision unit does not have the technical specifications and laws and regulations of the relevant safety production, and it cannot be corrected for some construction errors in time. At the same time, the construction site management is relatively chaotic, not in accordance with the construction procedures for construction, or even contrary to the construction procedures. Safety supervision and management departments for the supervision of the safety of the failure of the unit did not have more serious punishment, making the implementation of the safety responsibility of the supervisory enterprises is too lax, the supervisors failed to fulfill the duties of supervision and safety, the security problems are not tracked and reviewed in a timely manner.

Construction workers generally lack of safety awareness, the overall quality of the construction industry is low. At present, most of the construction workers in China are migrant workers, their working methods and knowledge structure and other aspects of their own factors have not been able to adapt to the construction industry, the special construction environment and working conditions, on the one hand, the construction staff generally did not go through strict Training, professional quality is not high, low security awareness; the other hand, the construction industry practitioners overall quality is low, relatively large mobility, combined with construction workers undocumented posts, construction operations are not standardized, resulting in the construction site there is a big Potential dangers.

Lack effective market incentives. At present, Chinese construction industry-related security compulsory insurance system is not perfect, although China has a general safety management in the field of laws and regulations, but if we only rely on laws and regulations to carry out mandatory regulation of security incidents, the effect can be described as very limited, We also need to take advantage of the huge adjustment of the market economy lever, the construction project parties to take the initiative to pursue the safety performance of the power to mobilize in order to fundamentally reverse the passive situation, but in the construction market, the market economy lever cannot effectively play Work out.

Building materials are unqualified and the construction is vulnerable to environmental factors. There is a defect in the construction materials, for example, the strength of the steel cannot meet the specifications, or in the construction process, in order to catch up with the progress, save money, not according to the design drawings, or even cut corners, resulting in the main building has not yet completed the cracks, collusion and other safety incidents; construction is different from the 
factory internal operations, mostly open-air operations and high-intensity physical operations, and the construction process, there are many variable environmental factors, such as temperature, noise, wind, fog, lighting and high concentration of dust and so on directly affect the construction staff of the operating mood, resulting in various types of construction safety accidents.

\section{Countermeasures of Construction Safety Accident}

In order to effectively prevent and reduce the occurrence of construction safety accidents in China, to further strengthen the construction safety management work, in view of the above construction safety accidents, especially the following countermeasures.

The insecure state of the object. The primary task of controlling the incidence of a safe accident is to isolate the insecure state of the object. For example: construction enterprises to purchase, lease the safety equipment, machinery (electrical) equipment, construction machinery and accessories, must have a production (manufacturing) permits, product certification, and entered the construction site before the inspection. In the use of the process, must be hand management, regular inspection, maintenance and repair, the establishment of data files, according to state regulations in a timely manner scrapped; machinery and equipment operators must be holders of posts, to prevent illegal operations; site safety inspectors to inspect the construction site, pay close attention to safety measures are in line with the rules and regulations; to strengthen the management of electricity, the implementation of a machine a box of a leak a protection, a box of more than one machine, the electrical daily record "electrical inspection record", cannot record running account; to ensure that corporate security funds in place in time, not arbitrarily diverted to other use; to be equipped with adequate security tools, clothing, etc., and simplify the safety protection tools and clothing collection procedures.

Fully embodies people-oriented. "People - oriented" is the construction of Chinese construction safety management in the principle of humanity. First of all, to improve the management of the quality of management, the implementation of strict reward and punishment system, the responsibility of the accident should be given economic penalties, administrative sanctions and even held criminally responsible. The implementation of safety production and economic benefits linked to the principle of safety production to make achievements and outstanding contributions of individuals, groups to carry out the necessary incentives; to cause accidents, individuals and groups must be severely punished.

Second, we must strengthen the safety education and training of workers. This is an important measure to reduce the "people's insecure state" caused by security incidents. Staff training and education is a long-term arduous work, construction enterprises to regularly carry out different forms, different levels, with targeted safety education and safety technical training, in particular, to strengthen the labor force and new workers and special types of workers Safety training and education for operators. Construction enterprises to organize safety education, training must not engage in form, go through the field, to implement safety education and training access system, to prevent unqualified personnel admission construction. So that safety education to be serious, strict, rigorous, rigorous, pragmatic. To achieve the safety and training of workers in the normalization, institutionalization, improve the safety of workers knowledge, safety skills and safety awareness, improve self-protection, strict compliance with operational procedures, to prevent illegal command, illegal operation, violation of labor discipline, the accident happened. In addition to reasonable arrangements for the construction organization design, to avoid the late construction period for the rush to extend the working hours, resulting in extreme physical and mental fatigue, resulting in security incidents. For the work of the larger, more technical process, the arrangements for workers to take into account the workers skilled in technical proficiency, character and temperament and other factors. To maximize the work for the workers to create a good working environment, pay attention to ventilation, lighting, dehumidification, noise reduction and other work, in the field to provide water, bath, bathroom and other living facilities. Always understand the difficulties and problems encountered by the workers in their family life and in their daily work, and give them material and 
spiritual help in time to get rid of their melancholy and anxious dilemma and concentrate on their work.

Establish a sound construction safety management system. The role of building safety management system is from the organization, the system to ensure the safety of production, smooth manner. Specifically, the establishment and improvement of building safety management system include: to speed up the legislative process, establish and improve the building safety laws and regulations system; enterprises in the Bank of effective safety management measures and methods developed into a unified standard, into the rules and regulations, establish and improve the building safety standard system ; Set up a full-time safety management agencies in the enterprise, equipped with full-time safety management personnel, establish and improve the building safety management organization system; clear enterprise departments, staff at all levels in the safety management work responsibilities and authority to implement safety production responsibility system, establish a sound system of building safety management responsibility system; strict implementation of the pre-job safety education and training shall not be on the system, the staff of the regular safety education and technical training, establish and improve the construction safety management training system; Regular on-site inspection, and consciously accept the industry to check the special inspection agencies, establish and improve the construction safety management audit system.

\section{Conclusion}

In general, the safety problem in construction is a difficult problem for the safe construction of our construction industry. The safety is related to the life safety of the construction workers and the harmony and stability of the society. Every one of our construction staff should pay attention to it. Adhere to the "people-oriented" and "safety first, prevention first" principle, pay attention to safety management, conscientiously implement the relevant laws and regulations in the construction industry to take effective safety precautions, and thus eliminate the construction safety risks, I believe that with Chinese economy the development and construction of the quality of the continuous improvement of the incidence of construction safety accidents will become increasingly low.

\section{References}

[1] Z. J. Zhang, Analysis and preventive measures of accident of tower crane in construction, J. Journal of Guangxi University. 44 (2010) 146-147.

[2] F. X. Han, Study on the safety of the accident tree in the construction of the fall and fall, J. Shanxi Architecture. 18(2005) 55-57.

[3] J. H. Zeng, Discussion on accident prevention of construction enterprises, J. Shanxi Architecture, 32(2012) 189-190.

[4] Y. J. Qi, How to prevent the construction of high fall accident, J. Technology economy market, $4(2007) 38-40$.

[5] Y. M. Ding, Cause Analysis of Six Damage Accidents in Construction, J. Shanxi Architecture, 9(2013) 142-150. 